\title{
Assessment of the Behavioural Problems among Adolescents of a Selected School in New Delhi
}

\author{
Fareha Khan', Neha John ${ }^{2}$ \\ ${ }^{1,2}$ Assistant Professor, Rufaida College of Nursing, Jamia Hamdard, New Delhi, India. \\ DOI: https://doi.org/10.24321/2349.2880.202109
}

\section{I $\quad \mathbf{N} \quad \mathbf{F} \quad \mathbf{O}$}

\author{
Corresponding Author: \\ Hamdard, New Delhi, India. \\ E-mail Id: \\ nehajohn1812@gmail.com \\ Orcid Id: \\ How to cite this article: \\ 2021;8(2):18-21. \\ Date of Submission: 2021-05-28 \\ Date of Acceptance: 2021-06-17
}

Neha John, Rufaida College of Nursing, Jamia

http://orcid.org/0000-0002-0653-2003

Khan F, John N. Assessment of the Behavioural Problems among Adolescents of a Selected School in New Delhi. Ind J Youth Adol Health.

\section{$\begin{array}{llllllll}\mathbf{A} & \mathbf{B} & \mathbf{S} & \mathbf{T} & \mathbf{R} & \mathbf{A} & \mathbf{C} & \mathbf{T}\end{array}$}

Introduction: Behavioural problems among school-going children are a matter of concern as they have serious consequences on the child, family, and society at large. Despite the high prevalence, there are very few studies related to behavioural issues among school children. The main objectives of the study were to assess and compare the behavioural problems among boys and girls.

Method: A quantitative research approach and comparative research design were used. A total of 100 adolescent boys and girls were chosen from the selected school of Delhi by convenient sampling techniques. A structured rating scale was used to assess the behavioural problems among adolescent boys and girls.

Result: The study showed that the majority of the participants (91\%) had mild behavioural problems, $8 \%$ had moderate behavioural problems, and only $1 \%$ was found with severe behavioural problems.

Conclusion: The study concluded that adolescents studying in school were having behavioural problems. The scores for eating disorders were more in boys than in girls whereas violent behaviour was equally common. Substance abuse was found to be the least common behavioural problem among both adolescent boys and girls.

Keywords: Behavioural Problems, Adolescent Boys and Girls, School

\begin{abstract}
Introduction
"Challenging behaviour" refers to any abnormal behavioural pattern that is above the expected norm for age and level of development. Such behaviour can include inappropriate vocalisation, self-injury, non-compliance, verbal or physical hostility, harming the environment, and numerous other stereotypes. These behaviours can have unfavourable consequences on the individual and require a lot of effort to be managed effectively and efficiently. ${ }^{1}$
\end{abstract}

A study was conducted in Kanpur, Uttar Pradesh, in which five hundred children aged $6-18$ years were randomly selected from a government school and were assessed for problems (behavioural, emotional, cognitive) using standardised tools. The study revealed that about $22.7 \%$ of children demonstrated behavioural, emotional or cognitive problems. Additional screening and evaluation tools showed that there was a higher prevalence of externalising symptoms among boys than girls. ${ }^{2}$

A study was conducted on the behavioural and emotional problems in school-going adolescents. The study showed that the prevalence of behavioural problems in adolescents was $30 \%$, with the prevalence being more in girls as compared to boys in all age groups. The most common psychiatric problem was internalising syndrome with a 
prevalence of $28.6 \%$. Stepwise regression analysis revealed that a perceived lack of emotional proximity to mother had the highest odds (3.489) followed by addiction in father (2.642) and marital discord in parents (1.402). Type of family, socioeconomic status, relationship with father and mother, and employment and educational status were not found to be significantly associated. ${ }^{3}$

\section{Materials and Methods}

The present study was aimed to assess and compare the behavioural problems among adolescent boys and girls for which a cross-sectional approach was adopted. The study was conducted from March to April 2019.

The present study was conducted in Hamdard Public School, Talimabad, Sangam Vihar, New Delhi. The population for the study included adolescent boys and girls. The sample size was 100 . The study included only those adolescents who were studying in school and were willing to participate. The study excluded adolescents who were less than 13 years of age or more than 18 years of age.
The questionnaire used for the study consisted of items on the demography profile and a rating scale to assess the behavioural problems among school adolescents. Permission was taken from the school authority and the consent of participating students was taken prior to data collection. Descriptive statistics were used to analyse the data and frequencies and percentages were used to describe the demographic variables of the subjects and for comparison of the extent of behavioural problems among adolescent boys and girls. Mean, modified mean, modified mean percentage, and rank order were used for comparison of the type of behavioural problems.

\section{Results}

Table 1 shows the results of the analysis of data. Majority of the participants were in the age group of $14-18$ years. The number of females was more than the number of males. With regard to religion, maximum number of respondents in the study sample were Muslims. As shown in Table 2, every adolescent had some degree of behavioural problems.

Table I.Frequency and Percentage Distribution of Sample Characteristics

\begin{tabular}{|c|c|c|c|}
\hline S. No. & Sample Characteristics & Frequency & Percentage \\
\hline \multirow{5}{*}{1.} & \multicolumn{3}{|l|}{ Age (years) } \\
\hline & $13-14$ & 3 & 3 \\
\hline & $14-16$ & 47 & 47 \\
\hline & $16-18$ & 48 & 48 \\
\hline & More than 18 & 2 & 2 \\
\hline \multirow{3}{*}{2.} & \multicolumn{3}{|l|}{ Gender } \\
\hline & Male & 39 & 39 \\
\hline & Female & 61 & 61 \\
\hline \multirow{6}{*}{3.} & \multicolumn{3}{|l|}{ Religion } \\
\hline & Hindu & 33 & 33 \\
\hline & Muslim & 64 & 64 \\
\hline & Christian & 0 & 0 \\
\hline & Sikh & 1 & 1 \\
\hline & Others & 2 & 2 \\
\hline \multirow{2}{*}{4.} & \multicolumn{3}{|l|}{ Marital status of parents } \\
\hline & Married & 100 & 100 \\
\hline \multirow{4}{*}{5.} & \multicolumn{3}{|l|}{ Family monthly income (in INR) } \\
\hline & Below 10,000 & 4 & 4 \\
\hline & $10,001-30,000$ & 22 & 22 \\
\hline & More than 30,000 & 74 & 74 \\
\hline \multirow{4}{*}{6.} & \multicolumn{3}{|l|}{ Number of siblings } \\
\hline & None (single child) & 7 & 7 \\
\hline & $1-2$ & 58 & 58 \\
\hline & More than 2 & 35 & 35 \\
\hline
\end{tabular}




\begin{tabular}{|c|c|c|c|}
\hline \multirow{3}{*}{7.} & \multicolumn{3}{|l|}{ Area of domicile } \\
\hline & Urban & 13 & 13 \\
\hline & Rural & 87 & 87 \\
\hline \multirow{4}{*}{8.} & \multicolumn{3}{|l|}{ Type of Family } \\
\hline & Nuclear & 72 & 72 \\
\hline & Joint & 22 & 22 \\
\hline & Extended & 6 & 6 \\
\hline \multirow{5}{*}{9.} & \multicolumn{3}{|c|}{ Are parents involved in any of the following? } \\
\hline & Smoking/tobacco & 11 & 11 \\
\hline & Alcohol & 1 & 1 \\
\hline & Drug abuse & 1 & 1 \\
\hline & None of the above & 86 & 86 \\
\hline \multirow{5}{*}{10.} & \multicolumn{3}{|c|}{ Are siblings involved in any of the following? } \\
\hline & Smoking/tobacco & 1 & 1 \\
\hline & Alcohol & 0 & 0 \\
\hline & Drug abuse & 1 & 1 \\
\hline & None of the above & 98 & 98 \\
\hline
\end{tabular}

Table 2.Frequency and Percentage of Extent of Behavioural Problems among Adolescent Boys and Girls

\begin{tabular}{|c|c|c|c|c|c|}
\hline Extent of Behavioural Problems & Score & Boys ( $\mathbf{n})$ & Boys (\%) & Girls (n) & Girls (\%) \\
\hline Mild or none & $1-23$ & 32 & 82.0 & 59 & 96.8 \\
\hline Moderate & $23-47$ & 6 & 15.4 & 2 & 3.2 \\
\hline Severe & $48-70$ & 1 & 2.6 & 0 & 0 \\
\hline
\end{tabular}

Table 3.Area-wise Mean, Modified Mean, Modified Mean Percentage, and Rank Order of Types of Behavioural Problems of Adolescent Boys and Girls

$\mathrm{n}_{1}+\mathrm{n}_{2}=100$

\begin{tabular}{|c|c|c|c|c|c|c|c|c|}
\hline \multirow{2}{*}{$\begin{array}{c}\text { Areas of } \\
\begin{array}{c}\text { Behavioural } \\
\text { Problems }\end{array}\end{array}$} & \multicolumn{2}{|c|}{ Mean Score } & \multicolumn{2}{|c|}{ Modified Mean } & \multicolumn{2}{c|}{$\begin{array}{c}\text { Modified Mean } \\
\text { Percentage }\end{array}$} & \multicolumn{2}{c|}{ Rank Order } \\
\cline { 2 - 9 } & Boys & Girls & Boys & Girls & Boys & Girls & Boys & Girls \\
\hline Violent behaviour & 4.23 & 4.19 & 0.52 & 0.52 & 1.33 & 0.85 & 3 & 1 \\
\hline Substance abuse & 0.58 & 0.13 & 0.14 & 0.03 & 0.35 & 0.04 & 7 & 7 \\
\hline Eating disorder & 2.51 & 1.95 & 0.62 & 0.48 & 1.58 & 0.78 & 1 & 2 \\
\hline Truancy & 2.46 & 1.88 & 0.61 & 0.47 & 1.56 & 0.77 & 2 & 3 \\
\hline $\begin{array}{c}\text { Delinquent } \\
\text { behaviour }\end{array}$ & 4.10 & 2.08 & 0.51 & 0.26 & 1.30 & 0.42 & 4 & 5 \\
\hline Sleeping pattern & 1.69 & 1.86 & 0.33 & 0.37 & 0.84 & 0.60 & 5 & 4 \\
\hline Homicide & 0.30 & 0.26 & 0.15 & 0.13 & 0.38 & 0.21 & 6 & 6 \\
\hline
\end{tabular}

Mean scores on the scale were more for violent behaviour, eating disorders, truancy and delinquent behaviour among boys whereas females had high scores in the areas of violent behaviour and delinquent behaviour. In the area of violent behaviour, the scores were almost the same among both boys and girls (Table 3 ).

\section{Discussion}

A cross-sectional study was conducted on 600 school-going adolescents between Class VIII to XII from the rural and urban areas in Kollam district using a cluster sampling method. The tool used was a self-reported SDQ. Approximately one-tenth of the study subjects reported having emotional 
and behavioural problems. The study showed a significant association in SDQ total score with the socioeconomic status of participants, type of schools, and settings using multiple regression analysis. It recommended regular assessment, early detection of problems, and intervention in schools by mental health professionals to help the adolescents with the various problems that they face and to ensure a healthy transition into their adulthood. ${ }^{4}$ The current study findings are in line with the quoted study which also depicts that majority of adolescents have behavioural problems.

Another study was conducted on 300 students of classes 9 th and 10th of Moga district of Punjab, which also shows all forms of aggression have an equal prevalence among boys and girls. A significantly higher proportion of females were found to be aggressive, angry, and hostile. ${ }^{5}$

This is in line with the present study which has highlighted that violent behaviours are prevalent among both adolescent boys and girls.

Early recognition and timely management of health problems in adolescents is important and teachers can play a significant role in this. ${ }^{6}$

\section{Conclusion}

The study shows that the adolescent boys and girls studying in school were having behavioural problems. In boys, the scores for eating disorders were more than in girls whereas violent behaviour was equally common. Substance abuse was found to be the least common behavioural problem in both adolescent boys and girls.

\section{Acknowledgement}

We would like to place on record the hard work and untiring efforts in the collection of data and the compilation of thesis of BSc Nursing Students of Rufaida College of Nursing, Jamia Hamdard, Delhi, namely Ms Gajala Amin, Ms Ilma Khan, Ms Isha, Ms Sana Parveen, and Ms Seema Azmi.

\section{Source of Funding: None}

\section{Conflict of Interest: None}

\section{References}

1. Ogundele MO. Behavioural and emotional disorders in childhood: a brief overview for paediatricians. World J Clin Pediatr. 2018 Feb 8;7(1):9-26. [PubMed] [Google Scholar]

2. Gupta AK, Mongia M, Garg AK. A descriptive study of behavioral problems in schoolgoing children. Ind Psychiatry J. 2017;26(1);91-94. [PubMed] [Google Scholar]

3. Pathak R, Sharma RC, Parvan UC, Gupta BP, Ojha RK, Goel N. Behavioural and emotional problems in school going adolescents. Australas Med J. 2011;4(1):15-21. [PubMed] [Google Scholar]
4. Harikrishnan U, Sailo GL. Prevalence of emotional and behavioral problems among school-going adolescents: a cross-sectional study. Indian J Community Med. 2021;46(2):232-5. [PubMed] [Google Scholar]

5. Garg I, Sethi S, Kishore J. The prevalence and patterns of aggression in school adolescents in a rural area of Moga District of Punjab, India. Indian J Youth Adol Health. 2018;5(1):43-46. [Google Scholar]

6. Salodia UP, Kumari S, Kishore J, Mandal RK. Effect of training on perception and knowledge of teachers towards common adolescent health problems in a school of Banglore. Int J Healthcare Edu \& Med Inform. 2017;4(2):4-9. [Google Scholar] 